\title{
BMJ Open Management of erectile dysfunction after prostate cancer treatment: cross- sectional surveys of the perceptions and experiences of patients and healthcare professionals in the UK
}

\author{
Amy Dyer, ${ }^{1}$ Mike Kirby, ${ }^{2,3}$ Isabel D White, ${ }^{4}$ Alison Michelle Cooper (D) ${ }^{1}$
}

To cite: Dyer A, Kirby M, White ID, et al. Management of erectile dysfunction after prostate cancer treatment: cross-sectional surveys of the perceptions and experiences of patients and healthcare professionals in the UK. BMJ Open 2019;9:e030856. doi:10.1136/ bmjopen-2019-030856

- Prepublication history and additional material for this paper are available online. To view these files, please visit the journal online (http://dx.doi. org/10.1136/bmjopen-2019030856).

Received 03 April 2019 Revised 15 August 2019 Accepted 16 August 2019

Check for updates

(C) Author(s) (or their employer(s)) 2019. Re-use permitted under CC BY-NC. No commercial re-use. See rights and permissions. Published by BMJ.

${ }^{1}$ Knowledge Team, Prostate Cancer UK, London, UK

${ }^{2}$ The Centre for Research in Primary and Community Care, University of Hertfordshire, Hatfield, Hertfordshire, UK ${ }^{3}$ The Prostate Centre, London, UK

${ }^{4}$ Department of Pastoral and Psychological Care, Royal Marsden NHS Foundation Trust, London, UK

\section{Correspondence to}

Dr Alison Michelle Cooper; knowledge@prostatecanceruk. org

\section{ABSTRACT}

Objectives Erectile dysfunction (ED) is known to be a common consequence of radical treatment for prostate cancer (PCa) but is often under-reported and undertreated. This study aimed to explore how ED in patients with PCa is managed in real-life clinical practice, from the perspective of patients and healthcare professionals (HCPs).

Design and setting This is a UK-wide cross-sectional survey of men with ED after treatment for PCa which covered assessment and discussion of erectile function, provision of supportive care and satisfaction with management. Parallel surveys of primary and secondary HCPs were also conducted.

Results Responses were received from 546 men with ED after PCa treatment, 167 primary (general practitioners and practice nurses) and 94 secondary care HCPs (urologists and urology clinical nurse specialists). Survey findings revealed inadequate management of ED in primary care, particularly underprescribing of effective management options. A fifth of men (21\%) were not offered any ED management, and a similar proportion (23\%) were not satisfied with the way HCPs addressed their ED concerns. There was poor communication between HCPs and men, including failure to initiate discussions about ED and/or involve partners, with $12 \%$ of men not told that ED was a risk factor of PCa treatment. These issues seemed to reflect poor access to effective ED management or services and lack of primary HCP confidence in managing $\mathrm{ED}$, as well as confusion over the roles and responsibilities among both HCPs and men. Conclusions This study confirms the need for better support for men from HCPs and more tailored and timely access to effective ED management after treatment for PCa. A clearly defined pathway is required for the discussion and management of ED, starting from the planning stage of PCa treatment. Improved adherence to ED management guidelines and better education and training for primary care HCPs are areas of priority.

\section{INTRODUCTION}

In 2018, 1.28 million men were diagnosed with prostate cancer worldwide, which represented $13 \%$ of all cancers diagnosed in men. ${ }^{12}$ In the UK, prostate cancer is the most
Strengths and limitations of this study

- This is the first UK study to survey the perceptions and experiences of men with erectile dysfunction after prostate cancer treatment and therefore adds considerable knowledge to the field.

- Also surveying primary and secondary healthcare professionals on the same topics revealed additional unique challenges in management coordination for these men.

- Limitations of this study include those inherent to surveys, particularly those dependent on retrospective recall of medical treatments and services offered or received.

- The survey sample contained a higher proportion of younger patients than the prostate cancer population as a whole, and compliance with erectile dysfunction treatment was not explored.

- The surveys were conducted before the availability of generic/over-the counter sildenafil and generic tadalafil.

common cancer in men, with over 56000 new cases diagnosed in 2018. ${ }^{3}$ Risk factors for prostate cancer include increasing age, ${ }^{4} \mathrm{a}$ family history of the disease in a first-degree relative, ${ }^{5-7}$ body weight ${ }^{8}$ and ethnicity-one in four black men will be diagnosed with prostate cancer in their lifetime in England, twice the risk of white men (one in eight). ${ }^{9}$

Radical treatments for prostate cancer include radical prostatectomy (RP), external beam radiotherapy (EBRT), brachytherapy, high-intensity focused ultrasound and androgen deprivation therapy (ADT). ${ }^{10} 11$ Active surveillance is also offered as an option to men with low-risk, and sometimes intermediate-risk, localised prostate cancer. ${ }^{10}$

While effective in prolonging survival, ${ }^{12}$ these treatments commonly induce erectile dysfunction (ED). ${ }^{13-15}$ The UK-wide Life After Prostate Cancer Diagnosis (LAPCD) study, 
examining patient-reported outcomes of over 30000 prostate cancer survivors at 18-42 months after diagnosis, recently reported that $81 \%$ of patients described their overall sexual function as poor or very poor. ${ }^{16}$ By comparison, the prevalence of poor sexual function in the general population of men aged 60 and over is $33 \% .{ }^{17}$

Typically, ED, accompanied by gradual structural changes in the penis, develops over a few months and up to 2-3 years after treatment and may be permanent. ADT may also cause loss of sexual interest, as well as more general symptoms such as fatigue, low mood, weight gain and decreased muscle mass. ED has been linked to loss of self-esteem and depression ${ }^{18}$ and can significantly impair quality of life for both men and their partners. ${ }^{13} 141619$

A wide range of treatments are available for the management of ED, including oral phosphodiesterase type 5 inhibitors (PDE5is), intracavernosal injections (ICI), intraurethral suppositories or ointment (alprostadil), vacuum erection devices (VED), and penile implants. ${ }^{101120}$ Nevertheless, ED remains an under-reported and often undertreated condition. ${ }^{21-24}$ The LAPCD study reported that only $44 \%$ of men were offered intervention(s) to help with sexual function, such as medications, devices or specialist services. ${ }^{16} \mathrm{~A}$ recent review from a high-volume centre suggested that despite the advancements in surgical technique and postoperative care, erectile function (EF) outcomes after RP have not improved over the last decade, and more efforts are needed to improve patients' care after RP. ${ }^{25}$

To address healthcare professionals' (HCP) concerns that no UK guidelines were available for the management of ED in patients with prostate cancer, specific consensus guidelines for treating ED after prostatectomy ${ }^{13}$ or radiotherapy/ADT ${ }^{14}$ have been developed. These guidelines emphasise the importance of proactive early sexual rehabilitation postprostatectomy, including patient education and pharmacological intervention, to minimise treatment-induced penile changes and to actively manage the impact of loss of sexual desire and delayed ED postradiotherapy/ADT on men and their partners.

The aim of this study was to explore how ED after prostate cancer treatment is experienced, assessed and managed in a publicly funded healthcare system, from the perspectives of both patients and HCPs. We conducted a UK-wide survey of men with ED after prostate cancer treatment and parallel surveys of primary and secondary HCPs, including general practitioners (GPs), practice nurses, urologists and urology clinical nurse specialists (CNS).

\section{METHODS}

\section{Study design and participants}

An online cross-sectional survey of men experiencing ED after prostate cancer treatment was conducted between August 2014 and March 2015. The survey consisted of a maximum of 48 questions and participants were told it would take $10-15 \mathrm{~min}$ to complete. Survey questions (online supplementary file 1) explored the assessment and discussion of EF with HCPs and satisfaction with ED management. To recruit participants, a hyperlink to the open online survey was widely disseminated through Prostate Cancer UK's communication channels, including electronic newsletters and social media. Paper versions of the survey were also provided on request, and these results were manually entered into the data set.

Online cross-sectional surveys of GPs, practice nurses, urologists and urology CNS were conducted between October 2014 and January 2015. The primary care survey consisted of a maximum of 16 questions, and the secondary care survey consisted of a maximum of 18 questions. All participants were told it would take $10 \mathrm{~min}$ to complete. Survey questions (online supplementary file 1) explored confidence regarding knowledge of prostate cancer and ED (primary HCPs only), discussions about potential side effects of prostate cancer treatment, how $\mathrm{EF}$ is assessed, the involvement of partners, ED management options, and roles and responsibilities. Participants were invited via Doctors.net.uk and Nursing in Practice access panels, weighted on gender, age and location to be representative of the respective HCP populations.

Questions for both surveys were coproduced and piloted with men living with and after prostate cancer and HCPs, through virtual working groups and face-toface workshops. Before beginning each survey, participants were informed of the approximate length of time to complete the survey, the purpose of the study, that their responses would be confidential and not used for any other purposes beyond this research study, and the contact details of the study team. Where appropriate, the online survey platform randomised the order that response options for a question were displayed in order to reduce bias. Only completed questionnaires were included in the final data set.

A Strengthening the Reporting of Observational Studies in Epidemiology checklist is provided in online supplementary file 2 .

\section{Statistical analysis}

Data were analysed based on the number and percentage of respondents to each question. For the survey of men with ED after prostate cancer treatment, responses were grouped and analysed by type of prostate cancer treatment received. HCP data were already split by profession at the time of data collection. Data were then pooled to compare between professions.

\section{Patient and public involvement statement}

The Prostate Cancer UK 'Policy \& Campaigns Forum', consisting of men living with and after prostate cancer, initially raised the issues around ED after prostate cancer treatment as a suggested area of work for Prostate Cancer UK to focus on. The Forum members were subsequently involved in the planning of the study, including development of the research questions and survey design. 
Table 1 Characteristics of survey respondents with erectile dysfunction after prostate cancer treatment $(n=546)$

\begin{tabular}{lc}
\hline Country & \\
\hline England & $400(73 \%)$ \\
\hline Scotland & $106(19 \%)$ \\
Wales & $37(7 \%)$ \\
\hline Northern Ireland & $3(1 \%)$ \\
\hline Total & $546(100 \%)$ \\
\hline Age (year) & \\
\hline$<50$ & $9(2 \%)$ \\
\hline $50-59$ & $118(22 \%)$ \\
\hline $60-69$ & $280(51 \%)$ \\
\hline $70-79$ & $120(22 \%)$ \\
$\geq 80$ & $19(3 \%)$ \\
\hline Total & $546(100 \%)$ \\
\hline Sexual orientation & \\
\hline Heterosexual & $513(94 \%)$ \\
\hline Gay & $17(3 \%)$ \\
\hline Bisexual & $13(2 \%)$ \\
\hline Total & $543(100 \%)$ \\
\hline Relationship status &
\end{tabular}

\section{Relationship status}

\begin{tabular}{lc} 
Married/civil partnership & $422(78 \%)$ \\
Have a partner, but not living together & $34(6 \%)$ \\
Do not currently have a partner & $36(7 \%)$ \\
Living with partner but not married/in civil & $31(6 \%)$ \\
partnership & \\
Widowed & $21(4 \%)$ \\
Total & $544(100 \%)$ \\
Years since first treatment for prostate cancer \\
20 and above & $3(1 \%)$ \\
$15-19$ & $21(4 \%)$ \\
$10-14$ & $55(10 \%)$ \\
$5-9$ & $181(33 \%)$ \\
$0-4$ & $286(52 \%)$ \\
Total & $546(100 \%)$ \\
Number of prostate cancer treatments received \\
1 & $356(66 \%)$ \\
2 & $160(30 \%)$ \\
3 & $26(5 \%)$ \\
Total & $542(100 \%)$ \\
\hline
\end{tabular}

Percentages have been rounded to whole numbers.

\section{RESULTS}

\section{Survey of men with ED after prostate cancer treatment} Respondent characteristics

Complete responses from 561 men with ED after prostate cancer were received (a self-selecting convenience sample). Responses from 15 men who had not received treatment in the UK were excluded, leaving a total of
546 respondents for analysis (table 1 ). The number of responses per question ranged from 408 to 546 (75\%$100 \%$ response rate) due to respondents selecting they did not know the answer or that the question did not apply to them.

The mean respondent age was 65 years, with half $(\mathrm{n}=280 / 546 ; 51 \%)$ of the study sample aged between 60 and 69 years (table 1$)$. Approximately half $(\mathrm{n}=286 / 546 ; 52 \%)$ of respondents had received their initial treatment for prostate cancer in the last 4 years. This sample closely resembles the prevalence data set of all patients with prostate cancer alive in England at the end of 2015, which shows 50\% living 0-5 years, 33\% $5-10$ years, $16 \% 10-15$ years and $5 \% 15-21$ years after diagnosis. ${ }^{26}$ The majority ( $\mathrm{n}=356 / 542 ; 66 \%$ ) of respondents had received only one treatment for prostate cancer, while $30 \%(n=160)$ received two and $5 \%(n=26)$ three. The most common treatment was RP $(n=310 / 546 ; 57 \%)$, either alone $(\mathrm{n}=258 ; 47 \%)$ or in combination with other treatment(s) $(\mathrm{n}=52 ; 10 \%)$. A quarter of patients $(\mathrm{n}=137 / 546$; $25 \%)$ received EBRT, and one-third $(\mathrm{n}=182 ; 33 \%)$ received ADT (online supplementary file 3).

Men's experiences prior to prostate cancer treatment

Almost three-quarters of respondents $(n=401 / 546 ; 73 \%)$ indicated that they had 'always' / 'almost always' been able to get and keep an erection before their prostate cancer treatment, with only $2 \% \quad(n=10)$ stating they were not sexually active before treatment (table 2 ).

Over one-third $(n=191 / 525 ; 36 \%)$ reported that their consultant was the first HCP to question them about their EF before treatment, while another third $(n=182 ; 35 \%)$ reported that no one had asked about this (table 2). Less than $10 \%(n=48 / 546 ; 9 \%)$ of respondents had completed a pretreatment standard questionnaire, such as the Sexual Health Inventory for Men (SHIM) ${ }^{27}$ or the International Index of Erectile Function (IIEF). ${ }^{28}$ Men who were to undergo prostatectomy were more likely to be asked to complete a questionnaire, compared with men who were to receive radiotherapy with $\mathrm{ADT}$ ( $14 \%$ vs $6 \%$, respectively).

Most respondents $(n=447 / 546 ; 82 \%)$ were told by their doctor or nurse that ED might be a side effect of their treatment; however, $12 \%(\mathrm{n}=68)$ were not told this information. This information was more likely to be given to men before a prostatectomy, compared with radiotherapy and ADT (91\% vs 74\%, respectively) (table 2). For respondents with a partner $(n=473), 70 \% \quad(n=332)$ said their partners were involved in these discussions with their HCPs. The knowledge of possibly experiencing erection difficulties influenced the choice of prostate cancer treatment for $13 \%(n=74 / 546)$ of men.

Men's experiences after prostate cancer treatment

Following prostate cancer treatment, half $(n=229 / 437$; $52 \%$ ) of men were asked about their EF by their HCP within 3 months (table 3), most commonly by their consultant, and this rose to $69 \%(\mathrm{n}=156)$ in the group that had a prostatectomy. However, 29\% $(n=127)$ of all respondents said they had not been asked by any HCP 
Table 2 Men's experiences prior to prostate cancer treatment

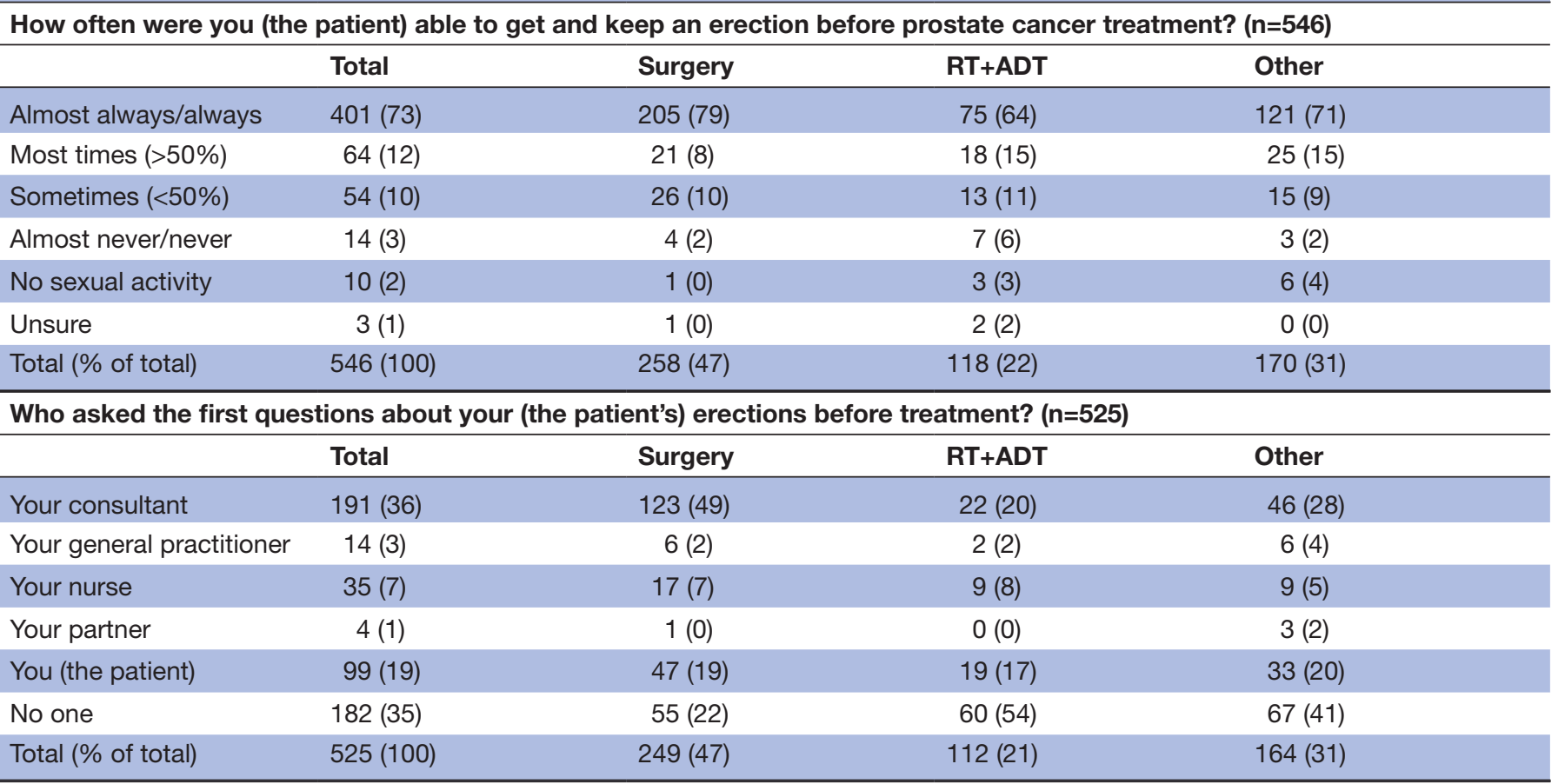

Did your (the patient's) doctor or nurse tell you (the patient) that erectile dysfunction might be a side effect of treatment? $(n=546)$

\begin{tabular}{lcccc}
\hline & Total & Surgery & RT+ADT & Other \\
\hline Yes & $447(82)$ & $235(91)$ & $87(74)$ & $125(74)$ \\
No & $68(12)$ & $11(4)$ & $21(18)$ & $36(21)$ \\
Unsure & $28(5)$ & $10(4)$ & $1(1)$ & $9(5)$ \\
$\begin{array}{l}\text { Erectile dysfunction not a } \\
\text { side effect of the treatment } \\
\text { I had }\end{array}$ & $3(1)$ & $2(1)$ & & $0(0)$ \\
Total (\% of total) & $546(100)$ & $258(47)$ & $118(22)$ & $170(31)$ \\
\hline
\end{tabular}

Percentages in brackets are a percentage of each column, unless otherwise stated.

'Other': all men who received a treatment other than 'surgery' or 'RT+ADT'.

'Total': all men who took part in the survey and reported erectile dysfunction following treatment.

'Surgery': men whose only radical treatment was radical prostatectomy.

'RT+ADT': men who only had radiotherapy (external beam radiotherapy and/or brachytherapy) plus ADT.

ADT, androgen deprivation therapy; RT, radiotherapy.

about EF following prostate cancer treatment (table 3). Almost a quarter $(\mathrm{n}=123 / 489 ; 23 \%)$ of men were not satisfied with the way HCPs addressed their EF concerns.

\section{Treatment for ED}

Two-fifths of men (n=199/503; 40\%) said they were offered ED treatment within 3 months of their prostate cancer treatment, with a further $19 \%(n=94)$ being offered treatment within 4-6 months. A fifth of men $(\mathrm{n}=110 ; 22 \%)$ said they were not offered any treatment (table 3). Treatment was most commonly offered by a consultant $(\mathrm{n}=230 / 516 ; 45 \%)$ and usually in a urology department $(\mathrm{n}=181 / 503 ; 36 \%)$, GP surgery $(\mathrm{n}=120 ; 24 \%)$ or ED clinic $(\mathrm{n}=89 ; 18 \%)$.

ED management options men received for ED are shown in online supplementary file $4(\mathrm{n}=521)$-most commonly men were offered three options $(n=122 / 521$;
$29 \%)$. The most common treatments offered were sildenafil 25,50 or $100 \mathrm{mg}(16 \%, 20 \%, 17 \%)$, VED (33\%), tadalafil 5, 10 or $20 \mathrm{mg}(21 \%, 14 \%, 29 \%)$, and pelvic floor exercises $(20 \%)$, mostly on National Health Service (NHS) prescription. The most common treatments prescribed privately were also PDE5is and VED.

When asked whether they had any difficulty or delays in getting access to ED treatment, a quarter $(n=103 / 431$; $25 \%$ ) indicated experiencing such problems. These included issues with supply and availability, such as 'restricted availability due to limited prescriptions', 'pharmacies lacking stock', 'cost' and 'HCPs not being helpful/ willing to prescribe/lacking knowledge'.

Monitoring of ED treatment

Over three-quarters of respondents $(\mathrm{n}=374 / 484 ; 77 \%)$ said they were not asked to complete a questionnaire 
Table 3 Men's experiences after prostate cancer treatment

How soon after prostate cancer treatment, if at all, did the consultant, GP or nurse ask whether your ability to get or keep an erection had been affected? $(n=437)$

\begin{tabular}{lcccc}
\hline & Total & Surgery & RT+ADT & Other \\
\hline$\leq 3$ months & $229(52)$ & $156(69)$ & $29(33)$ & $44(35)$ \\
$4-6$ months & $59(14)$ & $34(15)$ & $7(8)$ & $18(14)$ \\
$7-12$ months & $16(4)$ & $5(2)$ & $4(5)$ & $7(6)$ \\
$>12$ months & $6(1)$ & $1(<1)$ & $1(1)$ & $4(3)$ \\
Not at all & $127(29)$ & $29(13)$ & $46(53)$ & $52(42)$ \\
Total (\% of total) & $437(100)$ & $225(51)$ & $87(20)$ & $125(29)$ \\
\hline
\end{tabular}

How long after prostate cancer treatment, if at all, were you offered treatment to help you get or keep an erection? $(n=503)$

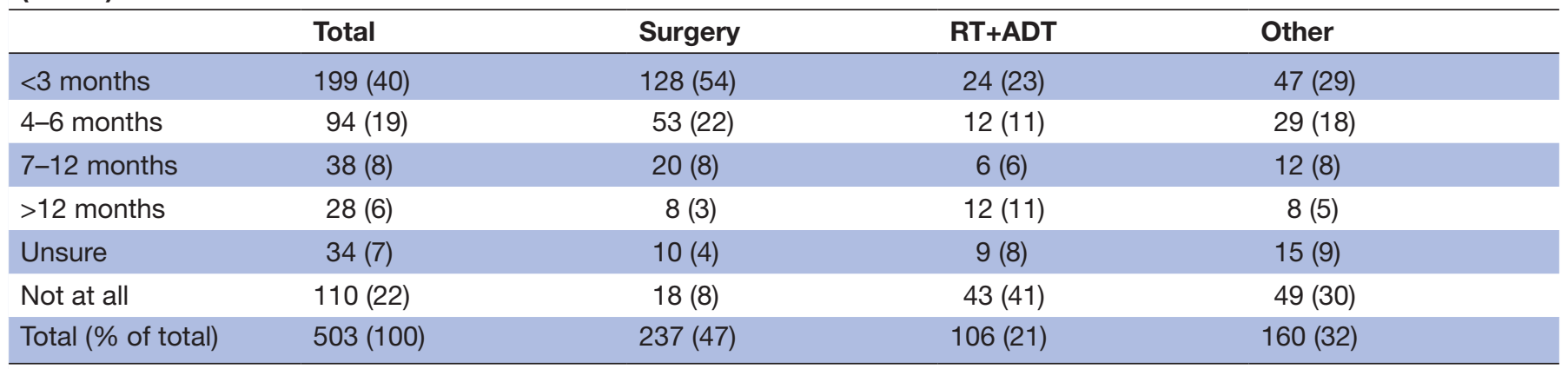

Percentages in brackets are a percentage of each column, unless otherwise stated.

'Other': all men who received a treatment other than 'surgery' or 'RT+ADT'.

'Total': all men who took part in the survey and reported erectile dysfunction following treatment.

'Surgery': men whose only radical treatment was radical prostatectomy.

'RT+ADT': men who only had radiotherapy (external beam radiotherapy and/or brachytherapy) plus ADT.

ADT, androgen deprivation therapy; GP, general practitioner; RT, radiotherapy.

about their erections, such as the SHIM or IIEF, during ED treatment. When asked whether their prescribed ED treatment met their needs, only $32 \% \quad(n=128 / 402)$ said 'yes', while $51 \%(\mathrm{n}=204)$ said 'no' and $17 \%(\mathrm{n}=70)$ were 'unsure'. Approximately half of the respondents $(\mathrm{n}=298 / 546 ; 55 \%)$ reported having access to a CNS, with the remainder saying they did not have access or were uncertain.

\section{Survey of primary and secondary HCPS}

Respondent characteristics

Complete responses from $282 \mathrm{HCPs}$ were received. Twenty-one responses were excluded from the analysis due to duplicate entries, leaving a total of $261 \mathrm{HCPs}$ in the analysis (115 GPs, 52 practice nurses (4 of whom were nurse practitioners/advanced nurse practitioners), 50 urologists and 44 urology CNS) (table 4).

Knowledge and confidence in ED management within primary care GPs and practice nurses were asked how confident they were that their knowledge of prostate cancer, ED and treatment options for ED was sufficiently comprehensive and up-to-date to support men with prostate cancer. Most GPs indicated their knowledge as 'satisfactory'/"confident'/'very confident' for prostate cancer $(n=98 / 115$; $85 \%)$, for ED $(\mathrm{n}=104 ; 90 \%)$ and for treatment options for $\operatorname{ED}(n=108 ; 94 \%)$, compared with $48 \%(n=25 / 52)$,
$34 \%(\mathrm{n}=18)$ and $32 \%(\mathrm{n}=17)$ of practice nurses, respectively, with the remainder stating they were 'apprehensive' or 'extremely unconfident' (figure 1). When asked what would help to improve their confidence, the most common responses were 'training/education' and 'further information/literature/online resources'.

\section{Discussions about ED}

Only $26 \%$ of GPs $(n=30 / 115)$ and $32 \%$ of practice nurses $(n=16 / 51)$ said they 'usually' /'always' initiated a discussion about ED with men after prostate cancer treatment, with 29\% ( $\mathrm{n}=33)$ and $38 \%(\mathrm{n}=19)$ saying they 'rarely' or 'never' did so, respectively. This varied by gender for GPs, with $20 \%$ of male GPs $(n=13 / 64)$ saying they 'never'/'rarely' initiated a discussion, compared with $44 \%$ of female GPs $(n=17 / 39)$. The most common reasons GPs gave for not initiating a discussion about ED were that it 'wasn't a priority topic' or that 'the patient initiated the discussion'. However, $32 \%$ of GPs $(n=37 / 115)$ said that men 'rarely'/'never' initiated a discussion about ED with them, while $25 \%$ of practice nurses $(n=13 / 51)$ said the same. For GPs, this question varied less by gender than the previous question, with $33 \%$ of male GPs $(n=21 / 64)$ saying patients 'never'/'rarely' initiated a discussion with them, compared with $41 \%$ of female GPs $(n=16 / 39)$. 
Table 4 Characteristics of primary and secondary healthcare professionals survey respondents $(n=261)$

\begin{tabular}{|c|c|c|c|c|}
\hline & General practitioners & Practice nurses & Urologists & $\begin{array}{l}\text { clinical nurse } \\
\text { specialists }\end{array}$ \\
\hline \multicolumn{5}{|l|}{ Country } \\
\hline England & 97 (84\%) & 45 (91\%) & 41 (82\%) & 38 (86\%) \\
\hline Scotland & $10(9 \%)$ & $0(0 \%)$ & $4(8 \%)$ & $2(5 \%)$ \\
\hline Wales & $5(4 \%)$ & $4(6 \%)$ & $4(8 \%)$ & $3(7 \%)$ \\
\hline Northern Ireland & $3(3 \%)$ & $3(3 \%)$ & $1(2 \%)$ & $1(2 \%)$ \\
\hline Total & $115(100 \%)$ & $52(100 \%)$ & 50 (100\%) & $44(100 \%)$ \\
\hline \multicolumn{5}{|l|}{ Gender } \\
\hline Male & $64(62 \%)$ & Not asked & 40 (80\%) & Not asked \\
\hline Female & $39(38 \%)$ & & $10(20 \%)$ & \\
\hline Total & $103(100 \%)$ & & 50 (100\%) & \\
\hline \multicolumn{5}{|l|}{ Age (years) } \\
\hline Under 30 & $1(1 \%)$ & Not asked & $3(6 \%)$ & Not asked \\
\hline $30-39$ & $42(41 \%)$ & & 19 (38\%) & \\
\hline $40-49$ & 35 (35\%) & & $20(40 \%)$ & \\
\hline $50-59$ & $21(20 \%)$ & & $8(16 \%)$ & \\
\hline 60 or over & $4(4 \%)$ & & $0(0 \%)$ & \\
\hline Total & $103(100 \%)$ & & 50 (100\%) & \\
\hline \multicolumn{5}{|c|}{ Average number of patients with prostate cancer seen per month } \\
\hline $0-9$ & $85(74 \%)$ & $46(90 \%)$ & $3(6 \%)$ & Not asked \\
\hline $10-19$ & $11(10 \%)$ & 0 & $16(32 \%)$ & \\
\hline $20-29$ & $8(7 \%)$ & 0 & $10(20 \%)$ & \\
\hline $30-39$ & $10(9 \%)$ & $5(10 \%)$ & $10(20 \%)$ & \\
\hline $40-49$ & $0(0 \%)$ & 0 & $3(6 \%)$ & \\
\hline $50-59$ & $0(0 \%)$ & 0 & $2(4 \%)$ & \\
\hline $60-69$ & $0(0 \%)$ & 0 & $2(4 \%)$ & \\
\hline $70-79$ & $0(0 \%)$ & 0 & $0(0 \%)$ & \\
\hline 80-89 & $1(1 \%)$ & 0 & $2(4 \%)$ & \\
\hline $90-100$ & $0(0 \%)$ & 0 & 2 (4\%) & \\
\hline Total & 115 (100\%) & $51(100 \%)$ & 50 (100\%) & \\
\hline
\end{tabular}

Percentages have been rounded to whole numbers.

When secondary care HCPs were asked who was the most likely to initiate a discussion about ED, the majority of urologists $(\mathrm{n}=33 / 50 ; 61 \%)$ identified themselves, while for non-ED specialist CNS $(\mathrm{n}=34)$ the most common first choice was the patient $(\mathrm{n}=12 ; 35 \%)$, followed closely by the urologist or urology/uro-oncology CNS (both $n=11$; $32 \%)$. A fifth of urologists $(n=10 / 50 ; 20 \%)$ said that the duration of ADT would affect their decision whether to discuss ED with the patient, with the conversation more likely to take place for men on long-term ADT.

Involvement of partners in discussions about ED appeared to be more common in secondary care. Of the urologists, $40 \%(n=20 / 50)$ vs only $13 \%$ of GPs $(n=15 / 115)$ said they 'usually'/'always' involved men's partners in such discussions, while $24 \%$ of urologists $(n=12 / 50)$ vs
$60 \%$ of GPs $(n=70 / 115)$ said they 'rarely'/'never' did so. Among the nurses surveyed, $65 \%$ of CNS ( $n=28 / 43)$ said they involved partners, compared with only $12 \%$ of practice nurses $(n=6 / 51)$.

Assessment of EF in secondary care

The majority of CNS $(34 / 44 ; 77 \%)$ and urologists $(40 / 50$; $80 \%$ ) said they 'usually'/'always' performed a verbal baseline assessment of EF before treatment, with only $8 \%$ of urologists $(\mathrm{n}=4)$ saying they 'never'/'rarely' did this. Standardised questionnaires were used less frequently than verbal assessments by both urologists and CNS. Of the urologists $30 \%(\mathrm{n}=15 / 50)$ indicated that there were some patient groups they chose not to assess for baseline $\mathrm{EF}$, for example if they were very elderly, had advanced 
Prostate cancer

A

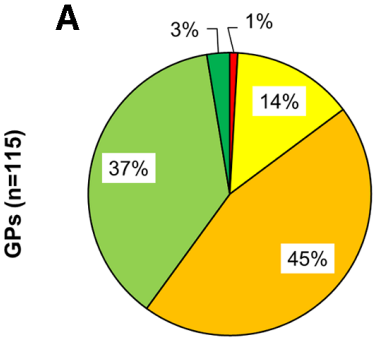

D

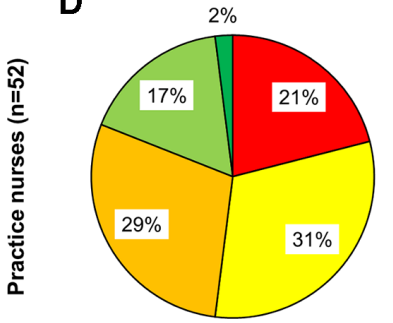

ED

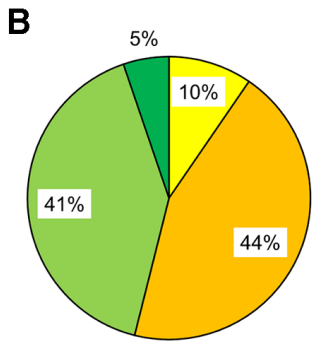

E

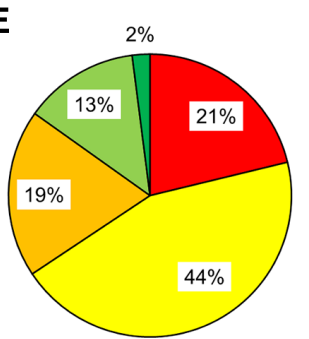

Treatment options for ED

C

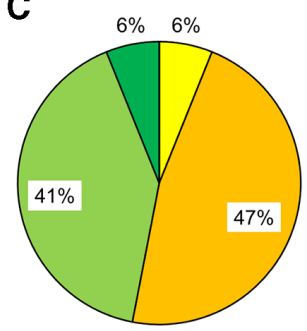

$\mathbf{F}$

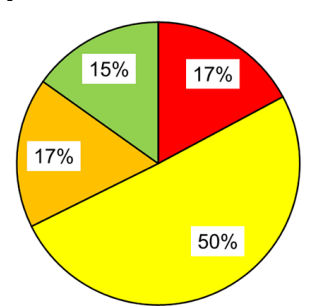

- Unconfident

$\square$ Apprehensive

口 Satisfactory

$\square$ Confident

$\square$ Very confident

Figure 1 Level of confidence among (A-C) GPs and (D-F) practice nurses that their knowledge of prostate cancer, ED and treatment options for ED is sufficiently comprehensive/up-to-date to support men with prostate cancer. GPs were asked two separate questions about comprehensive knowledge and up-to-date knowledge. The data shown are for comprehensive knowledge. Practice nurses were asked a single question about comprehensive/up-to-date knowledge. ED, erectile dysfunction; GPs, general practitioners.

disease or did not wish to be assessed. Other factors such as lifestyle, medication, comorbidities and relationships were also often included in the EF assessment.

\section{Roles and responsibilities}

Primary and secondary care HCPs were asked which HCPs or services they perceived as being involved in initiating, monitoring and following up on treatment for ED. The pattern of responses differed considerably between different HCP types, as shown in figure 2. GPs and urologists had the most prominent role according to GPs and practice nurses, whereas urologists and CNS identified themselves and dedicated ED services as playing the major roles. CNS identified themselves as having a greater focus on monitoring and follow-up, rather than on management initiation.

\section{Management of ED}

In primary care, $39 \%$ of GPs $(n=44 / 115)$ said that they 'usually'/'always' prescribed pharmacological management for men with ED after prostate cancer treatment, while $51 \%(n=59)$ said 'sometimes' and $11 \%(n=12)$ 'rarely'/'never' did. Only $23 \%$ of practice nurses $(n=12 / 52)$ said that they offered ED management.

A large majority of GPs $(\mathrm{n}=104 / 111 ; 94 \%)$ and urologists $(42 / 50 ; 84 \%)$ used oral therapy (PDE5is) as their first-line treatment for $\mathrm{ED}$ in patients with prostate cancer. The PDE5i most commonly prescribed by GPs was sildenafil (93\%), whereas urologists most commonly prescribed tadalafil (96\%). Most GPs prescribed a dose of four tablets per month; only $38 \%$ of GPs, compared with $69 \%$ of urologists, prescribed daily low-dose $(5 \mathrm{mg})$ tadalafil (the only daily PDE5i licensed for daily use).
GPs were much less likely than urologists to use secondline or third-line treatments, including VED (15\% vs $86 \%$ ), intracorporeal injections ( $35 \%$ vs $86 \%$ ), intraurethral prostaglandin E1 /alprostadil (17\% vs $58 \%)$, penile implants (9\% vs $28 \%$ ), combination therapy ( $1 \%$ vs $50 \%$ ),
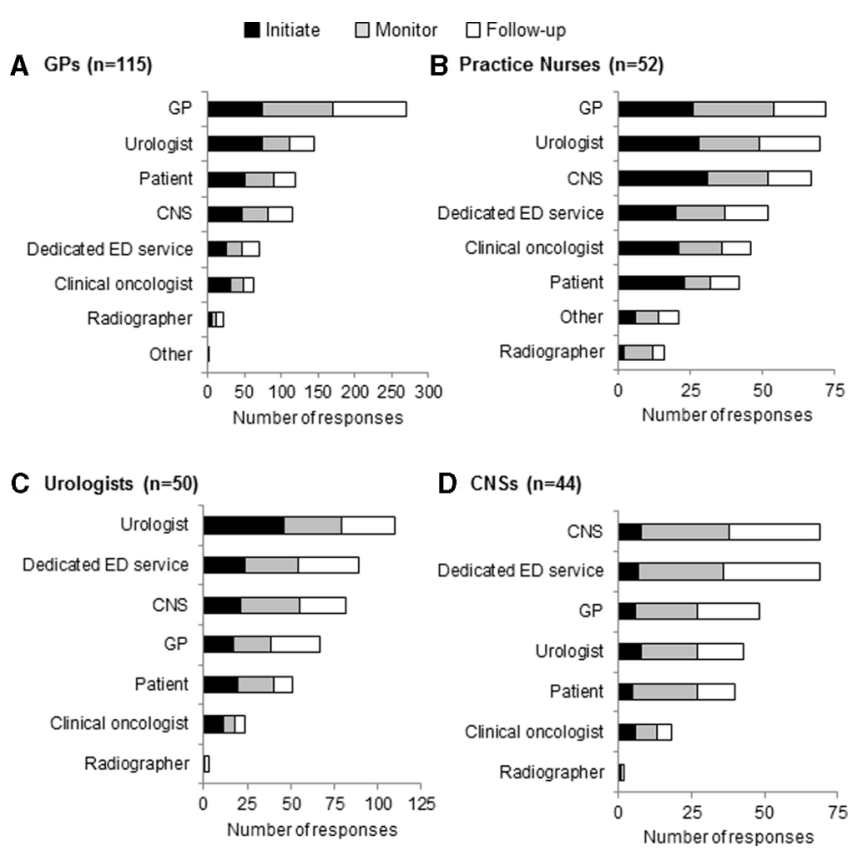

Figure 2 Roles and responsibilities of HCPs for the initiation, monitoring and follow-up of an ED management strategy according to (A) GPs, (B) practice nurses, (C) urologists and (D) CNS. HCPs could select more than one option from initiate (black), monitor (grey) or follow-up (white). ED, erectile dysfunction; GP, general practitioner; HCPs, healthcare professionals; CNS, clinical nurse specialist. 


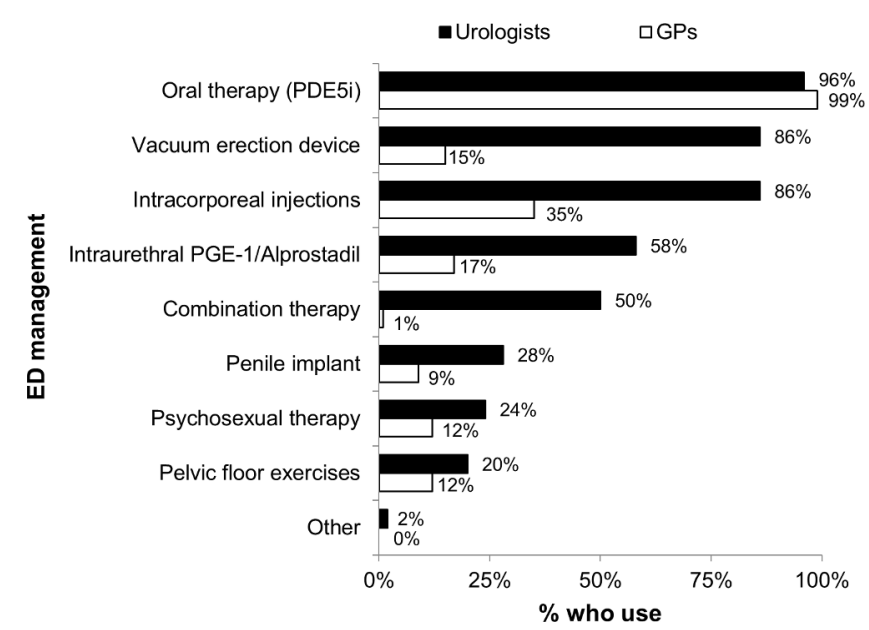

Figure 3 ED management strategies used after prostate cancer treatment by GPs $(n=115)$ and urologists $(n=50)$. Healthcare professionals could select more than one option. ED, erectile dysfunction; GPs, general practitioners; PDE5i, phosphodiesterase type 5 inhibitor; PGE-1, prostaglandin E1.

psychosexual therapy (12\% vs $24 \%)$ and pelvic floor exercises (12\% vs 20\%) (figure 3$)$. A common reason for this would be that GPs would refer the patient to secondary or specialist care for these treatments. However, $41 \%$ of GPs ( $\mathrm{n}=47 / 115)$ said they 'rarely'/'never' refer men with ED after prostate cancer treatment to secondary or specialist care.

\section{Access to treatments}

Treatments reported to be inaccessible to some GPs included penile implants $(\mathrm{n}=74 / 115 ; 64 \%)$, ICI $(\mathrm{n}=51$; $44 \%)$ and VEDs $(n=48 ; 42 \%)$. Common reasons given were that these treatments were 'restricted to secondary care', 'not prescribed on the NHS' or there was 'a lack of training or expertise in their use'. Treatment access was less of an issue among secondary care HCPs: $56 \%$ of urologists $(n=28)$ said that all ED treatments, including psychosexual therapy, were available to their patients.

\section{DISCUSSION}

Our survey of men explored the experiences of ED management after being treated for prostate cancer. In parallel surveys, we examined the knowledge and experience of primary and secondary HCPs in assessing such patients and their management strategies. Our findings indicated that, despite being at high risk from treatment-induced ED, many men were not treated according to recognised/available ED treatment guidelines available at the time of this study ${ }^{20} 29$ and many were dissatisfied with their ED management. There was also an apparent mismatch between patient and HCP views on how post-treatment ED is managed in practice. It seems likely that, to some extent, HCPs' responses may have reflected their 'ideal' management rather than what actually took place in practice.
Management of ED in primary care

In particular, there seemed to be inadequate management of ED in primary care, including failure to implement early and structured strategies, combination ED management strategies and, in some instances, any ED treatment at all. These issues seemed to reflect restricted access to treatments and services and lack of confidence in managing ED. This suggests a need for better targeted training and education, particularly for practice nurses. Many GPs see relatively few patients with prostate cancer, whereas practice nurses encounter men with ED more frequently, presumably when administering ADT injections or providing care for concomitant conditions, such as diabetes. In the UK there has been minimal undergraduate/postgraduate education in sexual medicine and human sexuality. ${ }^{30}$ We also found a lack of assessment of EF before and after prostate cancer treatment, with low usage of formal/validated measurement instruments (eg, IIEF, SHIM and so on) and no routine structured evaluation of ED management efficacy.

\section{Communication between HCPs and patients}

Communication between HCPs and patients was limited, with failures to initiate discussions about ED and/ or involve partners in discussions. It was particularly worrying that $12 \%$ of men said they were not told that ED was a risk of prostate cancer treatment. Communication barriers between patients and HCPs are known to be a key factor in the under-reporting, and consequent undertreatment, of ED. ${ }^{21}{ }^{22}$ Understandably, HCPs may be hesitant to enquire into the personal aspects of men's lives, which may explain why, in this study, female GPs were less likely to initiate a conversation about ED after prostate cancer treatment than male GPs. In addition, patients themselves may be too embarrassed to raise the issue, ${ }^{32} 33$ believe that ED is an inevitable result of ageing and/or not know which HCP to ask for help. ${ }^{22}$ Factors such as advanced patient age may deter GPs from enquiring about sexual activity. ${ }^{34} 35$

Although the men in our survey were not young (average age 65 years, with $25 \%$ aged $\geq 70$ years), it was clear from their survey responses that sexual activity was still important to them. Other reports suggest that many men wish to continue sexual activity into their eighth and ninth decades. ${ }^{36}$ Data from the diabetes setting have found patient embarrassment to be the most common reason for under-reporting of $\mathrm{ED} .^{32}$ In male patients aged $>30$ years attending their physician, a brief patient questionnaire on $\mathrm{EF}$ was found to be an excellent aid for patients and physicians to prompt discussion about ED. ${ }^{21}$ Patient reactions to the questionnaire included relief that the issue had been broached and the knowledge that help was available for ED. The Cancer Care Review (CCR), carried out by the GP or practice nurse within 6 months of the practice being notified an individual has a cancer diagnosis, is a component of the Recovery Package. ${ }^{38}$ The CCR is a useful opportunity to discuss side effects of treatment, as part of a wider discussion. Despite the 
availability of CCR templates and guidance, CCRs are not always conducted in a systematic and consistent manner, leading to variability in patient care and experience. ${ }^{39}$

As disease surveillance after treatment for prostate cancer generally occurs from 6 weeks post-treatment at 3-monthly intervals for at least 12 months in the UK, ${ }^{10}$ it was disappointing that there were delays in initiating ED management within secondary care and poor communication within primary care. The necessary focus on disease surveillance in oncology clinics may result in low prioritisation of sexual difficulties. An observational study found that patients with prostate cancer were more likely to initiate a discussion about sexual function in the urology clinic than in the clinical oncology clinic (22\% vs $4 \%$ ), but nevertheless sexual concerns were not discussed at all in almost $50 \%$ of visits. ${ }^{40}$

\section{Differences between HCP opinions}

Importantly, we found considerable differences between HCP opinions regarding lead roles in the initiation, monitoring and follow-up of ED management; such confusion could easily lead to inadequate management and contradictory advice, as was evident from the men's survey results. These findings may reflect financial considerations and, in the case of nurses, whether or not they have a prescribing role. The increased role of primary care in the follow-up of patients with prostate cancer ${ }^{41}$ requires unified management guidelines and support from Clinical Commissioning Groups regarding GP prescribing of relevant treatments with local guidelines and shared care protocols. While urologists and specialist ED clinics were most commonly identified as being responsible for prescribing ED treatment, this management route inevitably leads to delays, due to the need for specialist referral and limited access to specialist ED clinics.

Specific consensus guidelines for treating ED after prostate surgery ${ }^{13}$ and radiotherapy/ADT ${ }^{14}$ have been developed. These guidelines emphasise the importance of proactive early ED management, including patient education and pharmacological intervention, to minimise treatment-induced penile changes and the impact that loss of sexual desire and delayed ED may have on men and their partners. ${ }^{13} 1442-44$ The guidelines recommend daily and/ or on-demand PDE5is as first-line treatment for patients who have undergone nerve-sparing prostatectomy. ${ }^{13}$ PDE5is should be offered early after surgery, within the first month. ${ }^{44}$ VEDs, alone or in combination with other modalities, may be used if other treatments have proved ineffective.

\section{Access to treatments and specialist services}

The finding in this study that many GPs did not prescribe treatments for ED is a matter for concern. Surprisingly, $44 \%$ of urologists did not have access to all ED treatments, despite the National Institute for Health and Care Excellence guidance. ${ }^{10}$ NHS prescribing of PDE5is is often limited to once-weekly use, which may not adequately support men's needs or specialist sexual rehabilitation programme aims. ${ }^{46}$ 'Stinting' on effective treatments such as PDE5is can be a false economy, potentially resulting in treatment failure and the need for expensive secondary referrals. ${ }^{23}{ }^{24}$ It is hoped that the recent availability of reduced cost generic sildenafil and tadalafil, and the lifting of restrictions on its daily use, will allow more men with ED to receive early treatment.

Lack of access to specialist ED services is known to be a challenge for effective ED management, with support from nurses being identified as a significant factor impacting patient outcomes. Sexual counselling is known to contribute to better efficacy, patient acceptance of and compliance with other prescribed treatments for $\mathrm{ED},{ }^{13}$ but was rarely offered in our survey. The National Prostate Cancer Audit (NPCA) 2014 annual report included results of an organisational audit of prostate cancer services in England and Wales. The audit showed 'sexual function services' to be available in $90 \%$ of NHS Trusts in England and hospitals in Wales. ${ }^{47}$ However, at the time, these data were inconsistent with findings from Freedom of Information requests submitted by Prostate Cancer $\mathrm{UK}^{48}$ in 2015 to 235 NHS health authorities across the UK to determine the availability of services (ED clinics, psychosexual clinics and counselling/sexual therapy) and treatments (daily low-dose tadalafil, VEDs and penile implant surgery) for men with ED after prostate cancer treatment. These results indicated poor availability of ED clinics, with only $51 \%$ of areas stating they offered this service, with wide geographical variation. ${ }^{48}$ The NPCA repeated their organisational audit in 2016/2017 and $2018 / 2019$ and reported that 'sexual function services' were available in 100\% of NHS Trusts in England and Health Boards in Wales, either provided on site or by the specialist multidisciplinary team site. ${ }^{49}{ }^{50}$ Despite the published availability of support services, this does not necessarily translate through to men being offered intervention(s), accepting these interventions(s) or that these interventions are helpful. Although not yet proven to be effective, novel support approaches have been developed in a bid to tackle this problem, such as the Movember Foundation's TrueNTH initiative online self-management programme, which provides personalised self-management strategies to help improve sexual well-being after prostate cancer. ${ }^{51}$

\section{Limitations of the study}

Limitations of this study include those inherent to surveys, particularly those dependent on retrospective recall of medical treatments and services offered or received. Men and HCP surveys were conducted separately and some response options differed between surveys, limiting direct comparisons. While HCPs generally answered all questions, many of the men's survey questions were not answered and there were many 'unsure'/'don't know' or 'not applicable' responses. Men received a wide range of prostate cancer treatments-approximately half had undergone surgery (57\%)-but we were unable to determine how many had undergone nerve-sparing 
prostatectomy, since this question was not asked. Compliance with ED treatment was not explored and data on ethnicity were not collected. We did not conduct a separate analysis of data from gay and bisexual men, due to the small sample size, although recent data suggest that this group may have additional support needs than do heterosexual men. ${ }^{52}$ For the survey of men with prostate cancer, a 'convenience sample' was collected, which may limit generalisability of our results. The split by time since diagnosis was representative of all men living with and after prostate cancer in England as of 2015; however, the men in this study were younger than the prostate cancer population as a whole, with $25 \%$ aged 70 and over in this study, compared with $75 \%$ in the prostate cancer population. ${ }^{26}$ This is most likely explained by the use of online resources to recruit men into the study. As already noted, the surveys were conducted before the availability of generic and over-the-counter sildenafil and generic tadalafil.

\section{CONCLUSIONS}

In conclusion, our survey of men experiencing ED after prostate cancer treatment has confirmed findings in other published reports indicating that men living after prostate cancer treatment need better support from HCPs and more tailored and timely access to effective ED management. Results highlighted a lack of consensus over roles and responsibilities among HCPs: there needs to be a clearly defined pathway for discussion and management of ED, starting from the planning stage of prostate cancer treatment.

There is an urgent need for better education regarding ED management to be offered to primary care, particularly regarding the importance of early sexual rehabilitation, and for more high-quality evidence to support the recovery of sexual function following prostate cancer treatment.

Acknowledgements We thank all survey participants for contributing to and supporting our study. We wish to acknowledge the Prostate Cancer UK Policy \& Campaigns Forum members who, through their own personal experiences of living with and after prostate cancer, were involved in the development of this study. Thank you to Julia Balfour, of Northstar Medical Writing and Editing Services, who provided editorial support for this manuscript. We also wish to thank the past and present Prostate Cancer UK staff members who were involved in the design, conduct and analysis of this study.

Contributors AMC and AD designed and administered the surveys, analysed the data and drafted the manuscript. IDW and MK contributed to the study design, data interpretation and drafting of the manuscript. All authors edited the manuscript and gave final approval of the version to be published.

Funding This research was funded by Prostate Cancer UK.

Competing interests None declared.

Patient consent for publication Obtained.

Ethics approval This study did not require an application for ethical approval, in line with the NHS Research Ethics Committee decision tool (http://www.hradecisiontools.org.uk/ethics/). The study was assessed and approved by Prostate Cancer UK's Policy \& Campaigns Forum, consisting of men living with and after prostate cancer, and Leadership Team. By completing the survey, respondents were consenting to be part of the study and were informed that their responses would be confidential and not used for any other purposes beyond this research study.

Provenance and peer review Not commissioned; externally peer reviewed.

Data availability statement All data relevant to the study are included in the article or uploaded as supplementary information.

Open access This is an open access article distributed in accordance with the Creative Commons Attribution Non Commercial (CC BY-NC 4.0) license, which permits others to distribute, remix, adapt, build upon this work non-commercially, and license their derivative works on different terms, provided the original work is properly cited, appropriate credit is given, any changes made indicated, and the use is non-commercial. See: http://creativecommons.org/licenses/by-nc/4.0/.

ORCID iD

Alison Michelle Cooper http://orcid.org/0000-0002-0815-0084

\section{REFERENCES}

1 International Agency for Research on Cancer. All cancers fact sheet. Globocan 2018, 2018. Available: http://gco.iarc.fr/today/data/ factsheets/cancers/39-All-cancers-fact-sheet.pdf [Accessed 15 Aug 2019].

2 International Agency for Research on Cancer. Prostate cancer fact sheet. Globocan 2018, 2018. Available: http://gco.iarc.fr/today/data/ factsheets/cancers/27-Prostate-fact-sheet.pdf [Accessed 15 Aug 2019].

3 International Agency for Research on Cancer. United Kingdom fact sheet. Globocan 2018, 2018. Available: http://gco.iarc.fr/today/ data/factsheets/populations/826-united-kingdom-fact-sheets.pdf [Accessed 15 Aug 2019].

4 Cancer Research UK. Prostate cancer incidence statistics - By age (2014 - 2016). Cancer Res. UK, 2019. Available: https://www. cancerresearchuk.org/health-professional/cancer-statistics/statisticsby-cancer-type/prostate-cancer/incidence [Accessed 15 Aug 2019].

5 Bruner DW, Moore D, Parlanti A, et al. Relative risk of prostate cancer for men with affected relatives: systematic review and meta-analysis. Int J Cancer 2003;107:797-803.

6 Johns LE, Houlston RS. A systematic review and meta-analysis of familial prostate cancer risk. BJU Int 2003;91:789-94.

7 Kiciński M, Vangronsveld J, Nawrot TS. An epidemiological reappraisal of the familial aggregation of prostate cancer: a metaanalysis. PLoS One 2011;6:e27130.

8 World Cancer Research Fund. Diet, nutrition, physical activity and prostate cancer (2014 - revised 2018), 2018. Available: https://www. wcrf.org/sites/default/files/Prostate-cancer-report.pdf

9 Lloyd T, Hounsome L, Mehay A, et al. Lifetime risk of being diagnosed with, or dying from, prostate cancer by major ethnic group in England 2008-2010. BMC Med 2015;13:171.

10 National Institute for Health and Care Excellence. Prostate cancer: diagnosis and management [NG131], 2019. Available: https://www. nice.org.uk/guidance/NG131 [Accessed 15 Aug 2019].

11 Mottet N, Bellmunt J, Briers E, et al. EAU-ESTRO-ESUR-SIOG guidelines on prostate cancer, 2017. Available: https://uroweb.org/ wp-content/uploads/09-Prostate-Cancer_2017_web.pdf [Accessed 15 Aug 2019].

12 Hamdy FC, Donovan JL, Lane JA, et al. 10-Year outcomes after monitoring, surgery, or radiotherapy for localized prostate cancer. $N$ Engl J Med 2016;375:1415-24.

13 Kirby MG, White ID, Butcher J, et al. Development of UK recommendations on treatment for post-surgical erectile dysfunction. Int J Clin Pract 2014;68:590-608.

14 White ID, Wilson J, Aslet P, et al. Development of UK guidance on the management of erectile dysfunction resulting from radical radiotherapy and androgen deprivation therapy for prostate cancer. Int J Clin Pract 2015;69:106-23.

15 Resnick MJ, Koyama T, Fan K-H, et al. Long-Term functional outcomes after treatment for localized prostate cancer. N Engl J Med 2013;368:436-45.

16 Downing A, Wright P, Hounsome L, et al. Quality of life in men living with advanced and localised prostate cancer in the UK: a populationbased study. Lancet Oncol 2019;20:436-47.

17 Donnelly DW, Donnelly C, Kearney T, et al. Urinary, bowel and sexual health in older men from Northern Ireland. BJU Int 2018;122:845-57.

18 Nelson CJ, Mulhall JP, Roth AJ. The association between erectile dysfunction and depressive symptoms in men treated for prostate cancer. J Sex Med 2011;8:560-6.

19 McCabe MP, Althof SE. A systematic review of the psychosocial outcomes associated with erectile dysfunction: does the impact of 
erectile dysfunction extend beyond a man's inability to have sex? J Sex Med 2014:11:347-63.

20 Hatzimouratidis K, Salonia A, Adaikan G, et al. Pharmacotherapy for erectile dysfunction: recommendations from the fourth International consultation for sexual medicine (ICSM 2015). J Sex Med 2016;13:465-88.

21 Hartmann U, Burkart M. Erectile dysfunctions in patient-physician communication: optimized strategies for addressing sexual issues and the benefit of using a patient questionnaire. J Sex Med 2007;4:38-46.

22 Baldwin K, Ginsberg P, Harkaway RC. Under-Reporting of erectile dysfunction among men with unrelated urologic conditions. Int $J$ Impot Res 2003;15:87-9.

23 Hackett G. Nhs services for erectile dysfunction: a case of orchestrated chaos? Trends in Urology \& Men's Health 2011;2:32-5.

24 Hackett G. Stinting on sildenafil supply can prove costly. Trends Urology \& Men Health 2016;7:32-3.

25 Capogrosso P, Vertosick EA, Benfante NE, et al. Are we improving erectile function recovery after radical prostatectomy? analysis of patients treated over the last decade. Eur Urol 2019;75:221-8.

26 PHE National Cancer Registration and Analysis Service, Transforming Cancer Services Team for London, NHS, Transforming Cancer Services Team for London, NHS. Cancer prevalence in England. Local cancer Intell. Macmillan cancer support, 2018. Available: https://lci.macmillan.org.uk/England/all/prevalence [Accessed 15 Aug 2019].

27 Rosen RC, Cappelleri JC, Smith MD, et al. Development and evaluation of an abridged, 5-item version of the International index of erectile function (IIEF-5) as a diagnostic tool for erectile dysfunction. Int J Impot Res 1999;11:319-26.

28 Rosen RC, Riley A, Wagner G, et al. The International index of erectile function (IIEF): a multidimensional scale for assessment of erectile dysfunction. Urology 1997;49:822-30.

29 Hackett G, Kell P, Ralph D, et al. British Society for sexual medicine guidelines on the management of erectile dysfunction. J Sex Med 2008:5:1841-65.

30 Dixon-Woods $\mathrm{M}$, Regan J, Robertson N, et al. Teaching and learning about human sexuality in undergraduate medical education. Med Educ 2002;36:432-40.

31 Shindel AW, Baazeem A, Eardley I, et al. Sexual health in undergraduate medical education: existing and future needs and platforms. J Sex Med 2016;13:1013-26.

32 Grant PS, Lipscomb D. How often do we ask about erectile dysfunction in the diabetes review clinic? development of a neuropathy screening tool. Acta Diabetol 2009;46:285-90.

33 Gott M, Hinchliff S. Barriers to seeking treatment for sexual problems in primary care: a qualitative study with older people. Fam Pract 2003;20:690-5.

34 Gott M, Hinchliff S, Galena E. General practitioner attitudes to discussing sexual health issues with older people. Soc Sci Med 2004;58:2093-103.

35 Bauer M, Haesler E, Fetherstonhaugh D. Let's talk about sex: older people's views on the recognition of sexuality and sexual health in the health-care setting. Health Expect Int J Public Particip Health Care Health Policy 2016;19:1237-50.
36 Gott M, Hinchliff S. How important is sex in later life? the views of older people. Soc Sci Med 2003;56:1617-28.

37 Kalra G, Subramanyam A, Pinto C. Sexuality: desire, activity and intimacy in the elderly. Indian J Psychiatry 2011;53:300-6.

38 Royal College of General Practitioners. Recovery package. Available: https://www.rcgp.org.uk/clinical-and-research/resources/toolkits/ consequences-of-cancer-toolkit/recovery-package.aspx [Accessed 15 Aug 2019].

39 Adams $\mathrm{E}$, Boulton $\mathrm{M}$, Rose $\mathrm{P}$, et al. Views of cancer care reviews in primary care: a qualitative study. Br J Gen Pract 2011;61:e173-82.

40 Forbat L, White I, Marshall-Lucette S, et al. Discussing the sexual consequences of treatment in radiotherapy and urology consultations with couples affected by prostate cancer. BJU Int 2012;109:98-103.

41 Watson EK, O'Brien R, Campbell C, et al. Views of health professionals on the role of primary care in the follow-up of men with prostate cancer. Fam Pract 2011;28:647-54.

42 Stember DS, Mulhall JP. The concept of erectile function preservation (penile rehabilitation) in the patient after brachytherapy for prostate cancer. Brachytherapy 2012;11:87-96.

43 Mulhall JP, Bella AJ, Briganti A, et al. Erectile function rehabilitation in the radical prostatectomy patient. J Sex Med 2010;7:1687-98.

44 Salonia A, Burnett AL, Graefen M, et al. Prevention and management of postprostatectomy sexual dysfunctions. Part 1: choosing the right patient at the right time for the right surgery. Eur Urol 2012;62:261-72.

45 Salonia A, Castagna G, Capogrosso P, et al. Prevention and management of post prostatectomy erectile dysfunction. Trans/ Androl Urol 2015;4:421-37.

46 Barazani Y, Stahl PJ, Nagler HM, et al. Is there a rationale for penile rehabilitation following radical prostatectomy? Am J Mens Health 2015;9:35-43.

47 The Royal College of Surgeons of England. First year annual report - organisation of services and analysis of existing clinical data, 2014. Available: https://www.npca.org.uk/content/uploads/2018/ 02/NPCA-Annual-Report-FINAL-10_11_14-1.pdf [Accessed 15 Aug 2019].

48 Prostate Cancer UK. Prostate cancer patients 'abandoned to deal with erection problems alone.' Prostate Cancer UK, 2016. Available: https://prostatecanceruk.org/about-us/news-and-views/2016/ $11 /$ prostate-cancer-patients-abandoned-to-deal-with-erectionproblems-alone [Accessed 15 Aug 2019].

49 The Royal College of Surgeons of England. National Prostate Cancer Audit - Provider Results 2018. Natl. Prostate Cancer Audit 2018.

50 The Royal College of Surgeons of England. National Prostate Cancer Audit - Organisational Audit 2019. Natl. Prostate Cancer Audit 2019.

51 Movember Foundation. Maximising Sexual Wellbeing - Prostate Cancer. A self-management resource for people living with prostate cancer, 2019. Available: https://prostate.lifeguidewebsites.org/player/ play/prostate [Accessed 15 Aug 2019].

52 Ussher JM, Perz J, Kellett A, et al. Health-Related quality of life, psychological distress, and sexual changes following prostate cancer: a comparison of gay and bisexual men with heterosexual men. J Sex Med 2016;13:425-34. 